\title{
Five main processes in healthcare: a citizen perspective
}

\author{
Bo Bergman, ${ }^{1}$ Duncan Neuhauser, ${ }^{2}$ Lloyd Provost ${ }^{3}$
}

\begin{abstract}
${ }^{1}$ The Centre for Healthcare Improvement, Chalmers University of Technology Gothenburg, Sweden ${ }^{2}$ Department of Epidemiology and Biostatistics, Medical School, Case Western Reserve University, Cleveland, Ohio, USA ${ }^{3}$ Associates in Process Improvement, Austin, Texas, USA
\end{abstract}

Correspondence to Professor Bo Bergman, Chalmers University of Technology, Gothenburg, SE 41296, Sweden; bo.bergman@chalmers.se

Accepted 24 November 2010

\begin{abstract}
A citizen point of view on the healthcare system, its processes and their improvement is emphasised. From this point of view, five main processes are identified: Keeping Healthy, Detecting Health Problems, Diagnosing Diseases, Treating Diseases and Providing for a Good End of Life. The citizen should be looked upon as a cocreator of value and improvement of these processes.
\end{abstract}

\section{FIVE MAIN PROCESSES}

The concept 'work process' has been used for a very long time ${ }^{1}$ to denote sets of repeatable value creating activities subject to improvement. ${ }^{2}$ Shewhart ${ }^{3}{ }^{4}$ also emphasised the process as a means to produce value for the customer, but with a varying quality. By identifying and removing assignable causes of variation, the process could be made predictable with only chance causes of variation left in the process. Donabedian ${ }^{5}$ was an early proponent of the use of the process concept in healthcare. He identified the importance of looking at the organisational structure $^{6}$ and the processes involved in producing outcomes for the patients. Batalden and Stoltz, ${ }^{7}$ basing their contributions very much on Deming, ${ }^{8} 9$ extended the concept to systems by describing a general framework for quality improvement in healthcare.

Processes can be studied from a department, organisation ${ }^{10}$ or industry perspective. If we focus on the complete healthcare system, it would be natural also to look upon the processes from a citizen's point of view. From that perspective, the following five main processes are identified (figure 1).

\section{Keeping healthy (prevention)}

This paper is freely available online under the BMJ Journals unlocked scheme, see http://qualitysafety.bmj. $\mathrm{com} / \mathrm{site} / \mathrm{about} / \mathrm{unlocked}$. xhtml
This includes physical fitness, bed nets against malaria, a good diet, clean drinkingwater and less use of tobacco; the list goes on. We could have the best hospital care, but it would not achieve much if this first process is not functioning well. The use of personal improvement projects is a mechanism to improve health at the individual level. However, the healthcare system also has to engage in proactive prevention of future illness. If a 4-year old with a weight problem is left to habits already well developed, subsequent problems not only with health, such as increased risk of diabetes and subsequent consequences, but also social problems may arise. Another illustration is smoking cessation: societal support is important, as illustrated by successful legal activities in this area.

\section{Detecting health problems}

If people do not come forward, it can be difficult for the health system to help them. Proactive outreach on the part of the healthcare system is important. Cancer screening is an illustrative example. If a fastgrowing malign melanoma is growing without detection, the effectiveness of the diagnostic and treatment processes might be of little help. The citizens could be more actively engaged in monitoring their own health status. Longitudinal data are more useful if collected regularly. Daily measurement of hypertension or blood sugar can provide more information than can be collected once every few months in a doctor's office.

\section{Diagnosing diseases}

This is the process needed to trigger the next process of treatment. There are few things less cost-effective than the wrong diagnosis. Timeliness of diagnosis is critical for many disease paths. The healthcare system provides the knowledge and methods for this process.

\section{Treating diseases}

Curing and caring is at the core of most of today's discourse on quality improvement in 


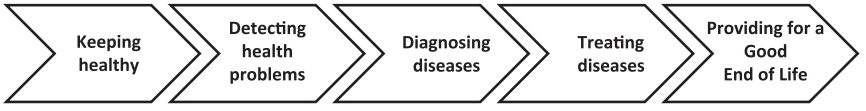

Figure 1 Five main processes in healthcare.

healthcare. Through self-management, the citizen can work as a stronger partner with the healthcare system to improve this process.

\section{Providing for a good end of life}

An effective, but endless treatment process is not always consistent with a good end of life. One shortcoming of an effective treatment process that is often not discussed is when the treatment obstructs the patients' quality of life in their last period of life. For many diseases, ageing is the root cause leading to the deterioration of all human systems-some slower, some faster. The medical specialties are divided by organ/symptom area: the heart, eyes, hearing, mental health, etc. What is considered good care from a symptom area specialist may not create a good end of life. A holistic point of view is required; therefore, there is a need for more physicians in the specialty of geriatric care.

\section{DISCUSSION}

Of course, these processes do not occur in neat succession; they may be in operation simultaneously, in parallel or iteratively. In happy situations, the first transforms into the last one. However, if any one of the four first processes goes wrong, subsequent processes will suffer as indicated in the illustrations above. When planning for improvement and allocating resources to the healthcare system, a systems view should be taken, and each and all of these interconnected processes should be considered; improvements made that impact citizens earlier in their life will be more valuable and usually more cost-efficient.

In the west of Sweden, steps have been taken to organise cancer processes from a patient/citizen point of view. This work is part of an action research project to gain more knowledge on improvement programmes that take this broad view of health. Process owners have been identified for each of 23 types of cancer. These owners have responsibility for the complete cancer system for their assigned cancer type. In addition, improvement work has begun on two generic subprocesses that span all the cancer types. The adoption of learning mechanisms to foster continual improvement of these processes is crucial. ${ }^{11}$

Taking the citizen's perspective on healthcare processes also requires a systems view and is an important step in the increased involvement of the citizens/ patients in the improvement of healthcare processes. The citizens are not just receiving value from the healthcare system; they are also active partners in their operation and should be important partners in its improvement. They should be seen as cocreators of value $^{12}$ rather than only subjects to the production in the healthcare processes.

Acknowledgements We want to express our gratitude to the editors, anonymous reviewers and $\mathrm{S}$ Lifvergren, for valuable comments and suggestions.

\section{Competing interests None.}

Provenance and peer review Not commissioned; externally peer reviewed.

\section{REFERENCES}

1. Babbage C. On the Economy of Machinery and Manufactures, 1832 http://www.gutenberg.org/dirs/etext03/cnmmm10.txt (accessed 22 Jul 2010).

2. Gilbreth LM. Psychology of Management 1914. http://www. gutenberg.org/files/16256/16256-h/16256-h.htm (accessed 22 Jul 2010).

3. Shewhart WA. Economic Control of Quality of Manufactured Product Milwaukee, WI: American Society for Quality Control, 1980 (originally published 1931).

4. Shewhart WA. Statistical Method from the Viewpoint of Quality Control. Washington, DC: Graduate School of the Department of Agriculture, 1939.

5. Donabedian A. Evaluating the quality of medical care. Milbank Mem Fund Q 1966;44(Suppl):166-206.

6. Glickman SW, Baggett KA, Krubert CG, et al. Promoting quality: the health-care organization from a management perspective. Int $J$ Qual Health Care 2007;19:341-8.

7. Batalden PB, Stoltz PK. A framework for the continual improvement of health care. Jt Comm J Qual Improv 1993;19:424-47.

8. Deming WE. Out of the Crisis. Cambridge, MA: Center for Advanced Engineering Study, Massachusetts Institute of Technology, 1986.

9. Deming WE. New Economics for Industry, Government and Education. Cambridge, MA: MIT Press, 1993.

10. Hellström A, Lifvergren S, Quist J. Process management in healthcare: investigating why it's easier said than done. J Manuf Techn Management 2010;21:499-511.

11. Shani $A B$, Docherty $P$. Learning by design. Key mechanisms in organization development. In: Cummings TG, ed. Handbook of Organization Development. Thousand Oaks, CA: Sage Publications, 2008.

12. ledema R, Merrick E, Piper D, et al. Co-designing as discursive practice in emergency health services: the architecture of deliberation. J Appl Behav Sci 2010;46:73-91. 